\title{
Multiple Sclerosis and Poliomyelitis in Australasia
}

\author{
M. J. EADIE,* M.D., M.R.A.C.P. ; J. M. SUTHERLAND,* M.D., F.R.C.P.ED., F.R.A.C.P. ; \\ J. H. TYRER, $†$ M.D., M.R.C.P., F.R.A.C.P.
}

Brit. med. F., 1965, 1, 1471-1473

In recent years various workers-for example, Kurland (1952), Kurland and Westlund (1953), Alter, Allison, Talbert, and Kurland (1960), and Acheson, Bachrach, and Wright (1960) -have shown that in the northern hemisphere multiple sclerosis becomes increasingly prevalent with increasing distance from the equator. No comparable series of prevalence studies has yet been reported from the southern hemisphere, but in Australasia mortality statistics and a postal survey suggested that there is a similar gradient with latitude (Sutherland, Tyrer, and Eadie, 1962), and studies of the prevalence of multiple sclerosis in various regions of the State of Queensland, Australia, also suggest that this gradient occurs (Sutherland, Tyrer, Eadie, Casey, and Kurland, 1965).

A recent hypothesis suggested by Poskanzer, Schapira, and Miller (1963) to explain the geographical distribution is of interest. It is widely recognized that poliovirus infection is very common in infancy in areas with poor standards of sanitation (as in many parts of the tropics), yet paralytic poliomyelitis is rare. Where there are higher standards of sanitation (in general, in the more temperate zones) poliovirus infection occurs later in life and paralytic disease is more frequent. Poskanzer et al. (1963) drew attention to a resemblance between the geographical distributions of multiple sclerosis and clinical poliomyelitis, and to other features which suggested that the two diseases had similar epidemiological patterns. They postulated that multiple sclerosis, like paralytic poliomyelitis, represents an occasional neurological manifestation of a widespread subclinical enteric infection. For each disease, age at initial infection determines the chances of neurological involvement. From other data Schapira, Poskanzer, and Miller (1963) inferred that there may be some 20 years' delay between the original enteric infection and the subsequent development of multiple sclerosis.

Because of the potential importance of this hypothesis we felt that its factual background should be reviewed. (Poskanzer et al. (1963) did not publish figures for the geographical distri-

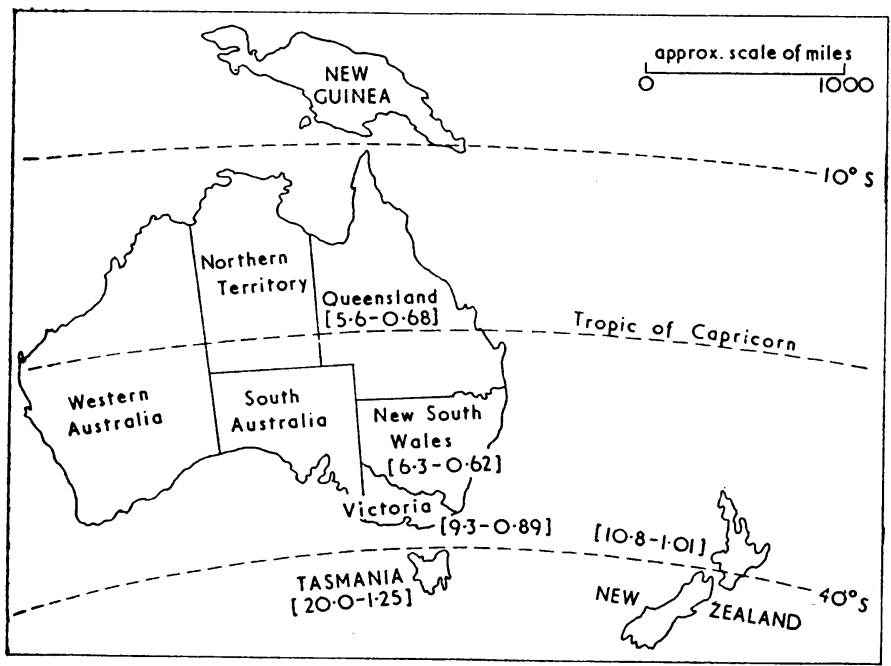

Fig. 1.-Map of Australasia, showing the regions studied, mean annual poliomyelitis notification rates, and multiple sclerosis mortality rates. butions of multiple sclerosis and poliomyelitis, and their reference for the latter distribution was dated 1918.) Such a review has involved the collection from the literature of poliomyelitis notifications and multiple sclerosis mortality and prevalence data for various countries, but we have been particularly concerned with the situation in Australasia, as this region is in some ways peculiarly suited to studies of the geographical occurrences of disease. Australasia's geographical extent is considerable-from 10 to 47 degrees south latitude (Fig. 1); its population is of very largely homogenous racial origin, the vast majority being of European and mainly British stock (the Australian aboriginal and New Zealand Maori population have been excluded from the present study) ; standards of living and medical care are reasonably uniform and are, in general, comparable with those of Western Europe ; there are no artificial boundaries that may limit the spread of infectious disease (Freyche and Nielsen, 1955) between the various parts of Australia ; and there is no restriction on travel between Australia and New Zealand.

\section{Method of Study}

Because of the postulated interval of about 20 years between enteric infection and the appearance of clinical multiple sclerosis, and the much shorter incubation period of poliovirus infection, poliomyelitis data more recent than 1950 were not considered. The estimated population of the country concerned in the middle year of the period under review (1921 to 1950 wherever full data were available) and the five-yearly figures given by Freyche and Nielsen (1955) were used to calculate the mean annual notification rates for poliomyelitis in various countries. These rates were compared with the multiple sclerosis mortality data for these countries from 1951 to 1958 (Goldberg and Kurland, 1962), and with field surveys of multiple sclerosis prevalence, where these were available.

For Australasia the relation between poliomyelitis and multiple sclerosis has been studied in states along the eastern seaboard of Australia (Queensland, New South Wales, Victoria, and Tasmania) and in New Zealand, as this selection permits a convenient correlation of disease occurrence with latitude (Fig. 1). The mean annual poliomyelitis notification rates for 1921 to 1950 for the Australian states and New Zealand were calculated from official statistics (Year Books of the Commonwealth of Australia, and W.H.O. data for New Zealand). The mean annual mortality rates for multiple sclerosis in the period 1950 to 1961 for the Australian states and New Zealand were calculated from data supplied by the Deputy Commonwealth Statistician for Queensland. Except for certain regions of Queensland (Sutherland et al., 1965), field surveys of multiple sclerosis prevalence in Australia are not available.

\section{Results}

Table I shows the mean annual poliomyelitis notification rates and multiple sclerosis mortality and prevalence rates for a

* Neurological Unit, Brisbane Hospital, Brisbane, Australia. † Medical Professorial Unit, Brisbane Hospital, Brisbane, Australia. 
number of northern and southern hemisphere countries ranked according to latitude. Because of the variations in multiple sclerosis prevalence found by different surveys within single countries, no attempt was made to correlate multiple sclerosis prevalence data with the other material under study. In the northern hemisphere countries there was no correlation between poliomyelitis notifications and multiple sclerosis mortality $(\mathbf{r}=-0.133 ; \mathrm{P}>0.90)$ (Fig. 2). Even if Iceland, with its very high poliomyelitis notification rate, were excluded, there would still be no correlation $(r=-0.148)$. In the few data available for southern hemisphere countries there was an apparent correlation $(r=+0.967)$ between poliomyelitis notification and multiple sclerosis mortality, but this was not statistically significant $(0.1<\mathrm{P}<0.2)$ (Fig. 3$)$.

In Australasia, where the geographical ranking has been arranged with much less overlap than obtained in the northern hemisphere countries, there is a high degree of correlation between latitude and poliomyelitis notification rate ( $\mathbf{r}$ rank $=+1.0)$, between latitude and multiple sclerosis

TABLE I.-Mean Annual Poliomyelitis Notification Rates, Multiple Sclerosis Mortality Rates, and Multiple Sclerosis Prevalence Data (Where Available) for Various Northern and Southern Hemisphere Countries. Ranking of Countries According to Latitude Has Been Done With the Aid of a Map Showing Population Densities

\begin{tabular}{c|c|c}
$\begin{array}{c}\text { Country } \\
\text { (Ranked According } \\
\text { to Latitude) }\end{array}$ & $\begin{array}{c}\text { Annual Polio } \\
\text { Notifications } \\
\text { per 105 } \\
(1921-50)\end{array}$ & $\begin{array}{c}\text { Annual } \\
\text { M.S. } \\
\text { Mortality } \\
\text { per 105 } \\
(1951-8)\end{array}$
\end{tabular} \mid$\quad$ M.S. Prevalence per $10^{5}$

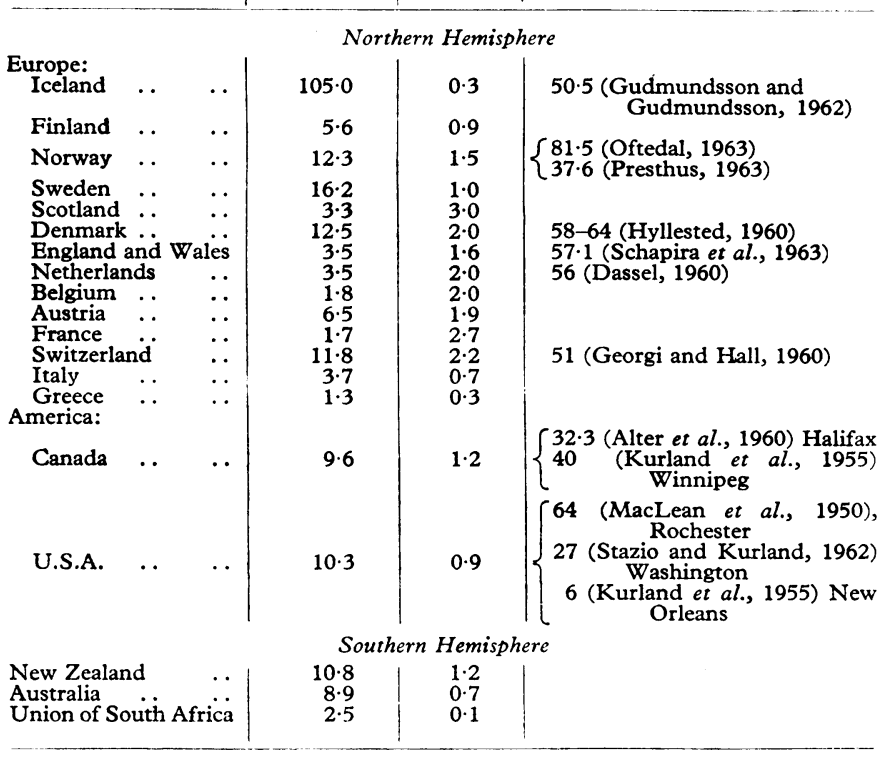

mortality ( $\mathrm{r}$ rank $=+0.9$ ), and between poliomyelitis notification rate and multiple sclerosis mortality $(\mathrm{r}=+0.952$; $0.01<\mathrm{P}<0.02$ ) (Table II, Fig. 4).

TABLE II.-Comparison of Poliomyelitis Notification and Multiple Sclerosis Mortality Data for Certain Regions of Australasia

\begin{tabular}{|c|c|c|c|}
\hline \multicolumn{2}{|c|}{$\begin{array}{l}\text { Region (Ranked According to } \\
\text { Increasing Distance } \\
\text { from Equator) }\end{array}$} & $\begin{array}{l}\text { Annual Polio } \\
\text { Notifications per } 10^{5} \\
\quad(1921-50)\end{array}$ & $\begin{array}{l}\text { Annual M.S. } \\
\text { Mortality per } 10^{5} \\
(1950-61)\end{array}$ \\
\hline $\begin{array}{l}\text { Queensland. } \\
\text { New South Wales } \\
\text { Victoria } \because \\
\text { New Zealand } \\
\text { Tasmania ... }\end{array}$ & $\begin{array}{l}\cdots \\
\therefore \\
\therefore \\
\cdots\end{array}$ & $\begin{array}{r}5 \cdot 6 \\
6 \cdot 3 \\
9 \cdot 3 \\
10 \cdot 8 \\
20 \cdot 0\end{array}$ & $\begin{array}{l}0.68 \\
0.62 \\
0.89 \\
1.01 \\
1.25\end{array}$ \\
\hline
\end{tabular}

\section{Discussion}

There are fallacies inherent in taking mortality statistics as an index of multiple sclerosis prevalence (Acheson, 1961), and particularly in using the formula (proportion of population affected by a disease $=$ annual death rate $\times$ duration of disease in years) (Brain, 1930). Nevertheless, at least for Queensland, mortality figures do provide a tolerable measure of multiple sclerosis prevalence. From mortality data the multiple sclerosis prevalence in Queensland would be about 13 per $10^{5}$ (Sutherland et al., 1962), and in a field survey of southern Queensland (in which part of the state the majority of the population lives) the actual prevalence was 11.9 per $10^{5}$ (Sutherland et al., 1965). If we presume the reliability of the multiple sclerosis mortality data for other parts of the world, and accept possible inaccuracies in poliomyelitis figures due to variation in notification standards and practices (Freyche and Nielsen, 1955), the present study has shown a rather better correlation between poliomyelitis notification, multiple sclerosis mortality, and latitude in Australasia than seems to apply for certain northern hemisphere countries. In these countries the relation between disease and latitude may be blurred by factors which do not apply in the less complicated epidemiological situation of Australasia.

Data for Australasia demonstrate the similarity between the geographical distributions of poliomyelitis and multiple sclerosis that is necessary to the hypothesis of Poskanzer et al. (1963). This, of course, is not proof of the hypothesis, but merely supplies one of the prerequisites to it. The hypothesis itself must be proved or disproved by other studies.

\section{Summary}

Poskanzer, Schapira, and Miller (1963) suggested that multiple sclerosis may be an occasional neurological manifesta-

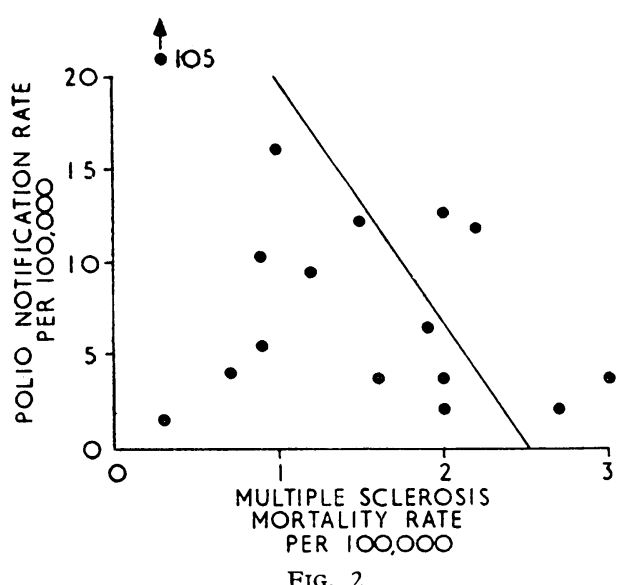

FIG. 2

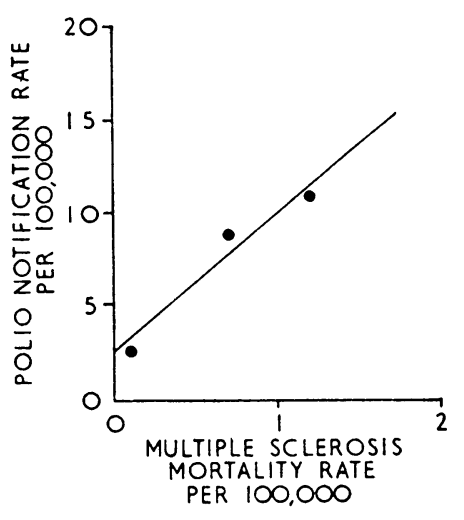

FIG. 3

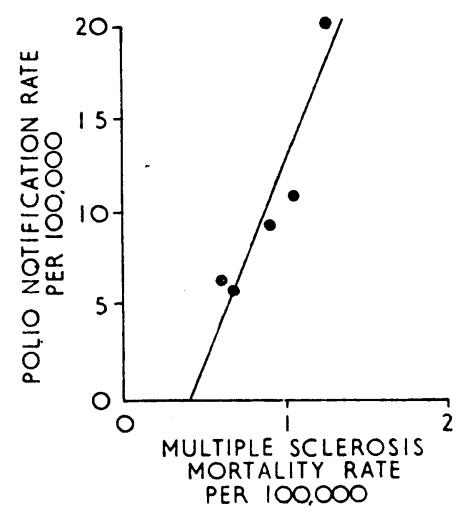

FIG. 4

FIG. 2.-Poliomyelitis notification rates and multiple sclerosis mortality data for certain northern hemisphere countries. The equation for the regression line is $y=-13.09 x+32.84$. FIG. 3.-Poliomyelitis notification rates and multiple sclerosis mortality data for certain southern hemisphere countries. The equation for the regression line is $y=7.72 x+2.28$. Fig. 4.-Poliomyelitis notification rates and multiple sclerosis mortality data for various regions of Australasia. The equation for the regression line is $y=21.62 x-8.85$. 
tion of a widespread enteric infection. This hypothesis was based on a suggested similarity between the geographical distributions of poliomyelitis and multiple sclerosis, though no actual data were given. One essential for this hypothesis has been supplied by the present study, which has confirmed the relation between multiple sclerosis mortality, poliomyelitis notification rate, and latitude in Australasia. Data from the northern hemisphere did not demonstrate this relation, possibly because there were more potential complicating factors in this hemisphere, and these may have exerted a masking effect.

We are grateful to Mr. S. E. Solomon, Deputy Commonwealth Statistician for Queensland, for his kindness in supplying multiple sclerosis mortality data for the Australian states and New Zealand.

\section{REFERENCES}

Acheson, E. D. (1961). Brit. 7. prev. soc. Med., 15, 118.

Bachrach, C. A., and Wright, F. M. (1960). Acta psychiat. scand., 35, Suppl. No. 147, p. 132 . Alter, M., Allison, R. S., Talbert, O. R., and Kurland, L. T. (1960).

Brain, W. R. (1930). Quart. f. Med., 23, 343.

Dassel, H. (1960). Acta psychiat. scand., 35, Suppl. No. 147, p. 64

Freyche, M. J., and Nielsen, J. (1955). Wld Hlth Org. Monogr. Ser., No. 26, pp. 59-106.

Georgi, F., and Hall, P. (1960). Acta psychiat. scand., 35, Suppl. No. 147, p. 75 .

Goldberg, I. D., and Kurland, L. T. (1962). Wld Neurol., 3, 444.

Gudmundsson, K. R., and Gudmundsson, G. (1962). Acta neurol. scand., 38, Suppl. No. 2 .

Hyllested, K. (1960). Acta psychiat. scand., 35, Suppl. No. 147, p. 30. Kurland, L. T. (1952). Amer. F. Hyg., 55, 457.

Mulder, D. W., and Westlund, K. B. (1955). New Engl. F. Med., 252, 649 .

MacLean, and 649.

Lean, A. R., Berkson, J., Woltman, H. W.; and Schionneman, L. (1950). Res. Publ. Ass. nerv. ment. Dis., 28, 25.

Oftedal (1963). Cited by R. S. Allison, Proc. roy. Soc. Med., 1963, 56, 71 .

Poskanzer, D. C., Schapira, K., and Miller, H. (1963). Lancet, 2, 917. Presthus (1963). Cited by R. S. Allison, Proc. roy. Soc. Med., 1963, 56, 71.

Schapira, K., Poskanzer, D. C., and Miller, H. (1963). Brain, 86, 315.

Stazio, A., and Kurland, L. T. (1962). Neurology (Minneap.), $12,445$.

Sutherland, J. M., Tyrer, J. H., and Eadie, M. J. (1962). Brain, 85, 149. lished.
A 56-year-old woman complained of palpitations and increasing breathlessness for one month prior to admission to hospital. For

\footnotetext{
- Senior House Officer in Medicine, St. James' Hospital, London. Now at New End Hospital, Hampstead, London.

+ House-physician, St. James' Hospital, London. Now at St. Bartholomew's Hospital Medical College, London.
}

one week she had noticed aching and some tenderness of the right side of the neck. In 1958, five years previously, she had been admitted with a myocardial infarction, confirmed by electrocardiograms, and followed by pulmonary embolism with effusion. There had been persistent tachycardia after this, and several episodes of congestive cardiac failure were treated with digoxin and diuretics. There was no history of ear disease at any time.

On examination she was dyspnoeic at rest and the jugular venous pressure was increased on the left. The right side of the neck was swollen and extremely tender. The thrombosed internal jugular vein was readily palpable as a solid cord, and some small, firm, mobile lymph nodes were present in the deep cervical chain. There was pitting oedema of the ankles. The pulse rate was 88 per minute, the blood pressure $140 / 90 \mathrm{~mm}$. $\mathrm{Hg}$, and the heart not clinically enlarged. There was a triple rhythm at the apex, but no murmurs were heard. Bilateral basal rales were audible in the chest.

In view of the presence of lymph nodes in association with the thrombosis of the internal jugular vein, exploration and lymphnode biopsy were carried out. The right internal jugular vein was found to be thrombosed and adherent to the surrounding tissues; nothing could be aspirated from it. There were several moderately enlarged lymph nodes adjacent to the vein. The histology of one of these showed non-specific reactive hyperplasia.

Examination in the E.N.T. department revealed no abnormality in the ears, nose, or nasopharynx. During this admission there was a brief episode of upper abdominal pain, severe, sharp in type, and without radiation. On examination there was deep epigastric tenderness but no other abnormal signs. Investigations, including barium-meal $x$-ray examination, serum amylase, and 24-hour urinary amylase, showed nothing abnormal. The pain settled spontaneously and there was no recurrence. When she was readmitted some 11 months later with a further myocardial infarction the neck was healed and there were no other abnormalities. Two months later the patient died in another hospital; no postmortem examination was permitted.

Investigations.-Haemoglobin 13.2 g./100 ml.; W.B.C. 8,500/ c.mm. ; erythrocyte sedimentation rate $30 \mathrm{~mm} . / 1$ hour (Wintrobe). Haematocrit, bleeding- and clotting-times, and platelet count were normal on several occasions. The serum cholesterol during the admission of 1958 was $325 \mathrm{mg} . / 100 \mathrm{ml}$. This remained elevated, but the patient was not a diabetic and there was no evidence of 